\title{
Assessment of CAD Related Items for a Concept Inventory for Engineering Graphics
}

\author{
Mr. Kaloki Nabutola, Embry-Riddle Aeronautical University, Daytona Beach \\ Dr. Heidi M. Steinhauer, Embry-Riddle Aeronautical University, Daytona Beach
}

Heidi M. Steinhauer is an Associate Professor of Engineering, Department Chair of the Engineering Fundamentals Department, co-advisor for the only all-women's Baja SAE Team, Founding Member of FIRST (Female Initiative Reaching Success Together), and former director for GEMS (Girls in Engineering, Math, and Science). Dr. Steinhauer's awards include the ABET Presidential Award of Diversity and a three time winner of the Women's Vision Award. She has presented papers at ASEE Annual Conference, the ASEE Global Colloquium, Research in Engineering Education Symposium, Engineering Design Graphics Division Mid-Year Conference, Additive Manufacturers Users Group, and Solid Free-Form Fabrication Symposium. Her research interests center around the development and assessment of students' spatial visualization skills, the effective integration of 3D modeling into engineering design, and the impact of contextualized hands-on applications on student learning and success. She has taught Engineering Graphics, Introduction to Engineering Design, Automation and Rapid Prototyping, Additive Manufacturing, and has developed several advanced applications of 3D modeling courses. Dr. Steinhauer received her B.S. in Aircraft Engineering and her M.S. in Systems Engineering, and her Ph.D. in Engineering Education from Virginia Tech.

\section{Dr. Theodore J. Branoff, Illinois State University}

Dr. Branoff is a professor and chair of the Department of Technology at Illinois State University. He taught engineering graphics, computer-aided design, descriptive geometry, and instructional design courses in the College of Education at North Carolina State University from 1986-2014. He also worked for SiemensSwitchgear Division and for Measurement Group, Inc. Dr. Branoff's research interests include constraintbased solid modeling strategies and spatial visualization abilities in undergraduate students. He has conducted CAD and Geometric Dimensioning and Tolerancing workshops for both industry and education professionals. Dr. Branoff served as President of the International Society for Geometry and Graphics from 2009-2012. In 2013 he was elected into the Academy of Fellows of the ASEE, and in 2014 he received the Distinguished Service Award from the Engineering Design Graphics Division of ASEE. In April of 2015 Dr. Branoff received the Orthogonal Medal for distinguished service in graphic science from the Technology, Engineering \& Design Education faculty at North Carolina State University.

\section{Dr. Nancy E. Study, Pennsylvania State University, Behrend}

Dr. Nancy E. Study is on the faculty of the School of Engineering at Penn State Behrend where she teaches courses in engineering graphics and rapid prototyping, and is the coordinator of the rapid prototyping lab. Her research interests include visualization and haptics. Nancy is a former chair of the ASEE Engineering Design Graphics Division and is currently the Circulation Manager and Treasurer of the Engineering Design Graphics Journal. She received her B.S. from Missouri State University, and M.S. and Ph.D. from Purdue University.

Dr. Craig L. Miller, Purdue University, West Lafayette
Dr. Steven Y. Nozaki, Ohio State University

$\mathrm{PhD}$ - Engineering Education, The Ohio State University MS - Civil Engineering, The Ohio State University 


\title{
Assessment of CAD Items for a Concept Inventory for Engineering Graphics
}

\begin{abstract}
Concept Inventories (CI) are designed to measure student understanding of fundamental concepts and have been used in education reform efforts for the past several decades. A CI for engineering graphics is currently being developed. The original intent of this graphics CI was to include both "modern" (i.e., CAD) and "traditional" (i.e., sketching, conventions, etc.) fundamental concepts. The first step in the development of any CI is to create open-ended problems. The incorrect results from these problems are used to determine common student misconceptions and ultimately form the distractors for the multiple choice items. In the initial round, the open-ended problems for traditional topics produced a variety of responses that could be clearly categorized from which distractors could then be readily identified. The traditional topics yielded one clearly correct answer. However, the open-ended problems for the CAD topics produced multiple responses that were difficult to interpret and categorize into discrete correct or incorrect classifications. Further, it was apparent that for each open-ended CAD item there were multiple correct solutions because optimal modeling strategies depend on design intent, CAD package used, and the desired manufacturing processes. Because the open-ended questions created by the researchers did not yield usable results, a series of multiple choice questions developed for assessment in a high school $C A D$ competency exam were identified as potential CI items. The research team reviewed this exam identifying several promising candidate items for inclusion in the CI. These items were then tested with a pool of students with CAD knowledge. This paper presents the results from the betatesting of these CAD items and addresses their suitability for use in the engineering graphics Concept Inventory.
\end{abstract}

\section{Introduction}

The use of Concept Inventories has become increasingly popular as a method to measure student learning and potentially reform teaching methods. The incorrect responses reveal misconceptions which can be useful in evaluating instruction. Researchers involved in science education have used pre- and post- assessments to measure student learning and validate the need for curriculum revision [1]. Engineering Graphics has been identified as a field in which the use of a CI could expose common misconceptions associated with graphic representation, as well as identify the fundamental concepts that contribute to the generation of those graphics. With varying curricula across institutions it can be expected that the implementation of engineering graphics will differ. The development of a standardized instrument to assess the understanding of concepts related to engineering graphics could be beneficial in streamlining or standardizing instruction across institutions and ensuring that deep-seated misconceptions are corrected.

CAD instruction varies widely across universities due to instructors having different professional and educational backgrounds and the diverse CAD software packages used. For example, 
instructors with a manufacturing background may have a predisposition towards either additive modeling, a design process involving adding material from a base sketch or profile, or subtractive modeling, a design process involving taking material away from a generic mass until the desired object is achieved, both of which mimic manufacturing processes and would affect their CAD instruction.

Figure 1a is a part modeled in CATIA using the Shaft command (commonly known as Revolve in other packages) on a simple profile. This is an example of an additive design process because it involves adding material from a base sketch. Figure $1 \mathrm{~b}$ is part modeled in CATIA using the Pad (commonly known as extrude in other packages) and groove command on two separate sketches.
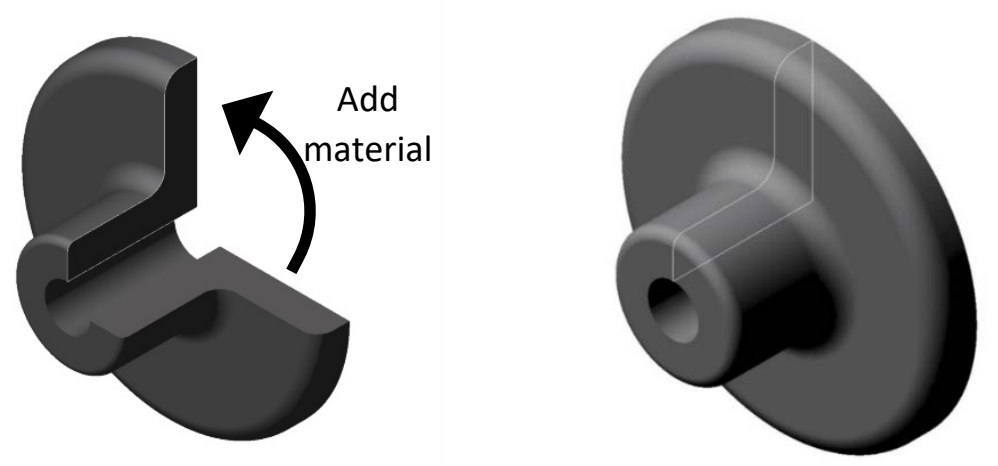

Figure 1a: Part Modeled in CATIA Additive Method
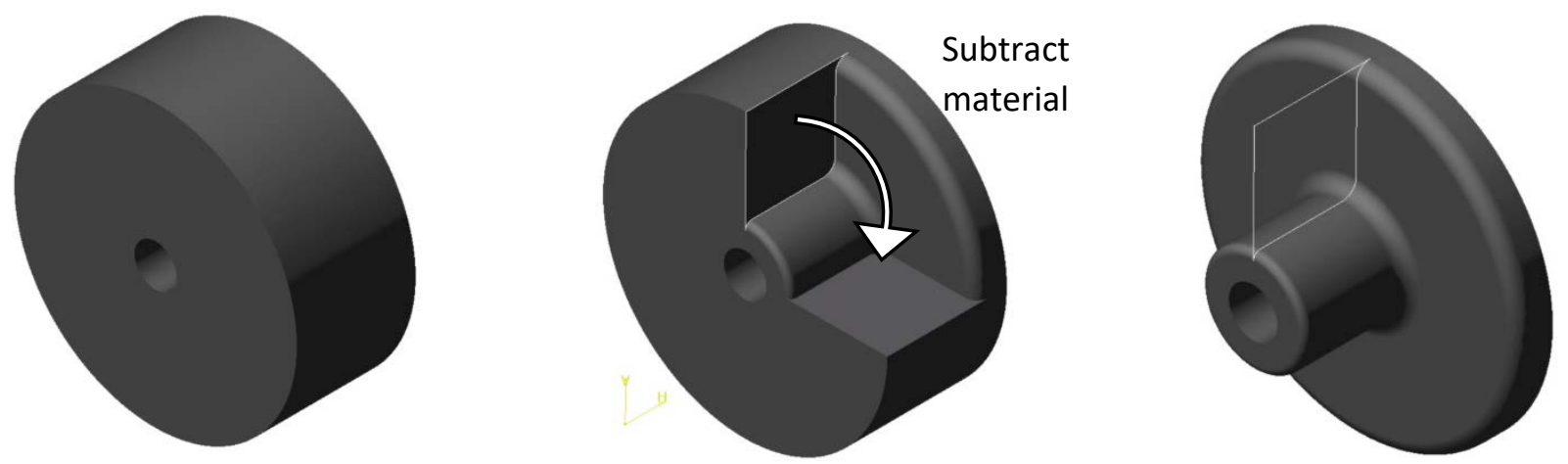

Figure 1b: Part Modeled in CATIA Subtractive Method 
Some instructors might argue that Figure 1 is incorrect because it has not been modeled in a stable orientation. Yet another instructor, one with a manufacturing background, might claim that it is modeled incorrectly because it could not be 3D printed or milled in its current orientation. While other instructors would argue the part is in the correct orientation in relation to its assembly. Additionally, instructors have different preferences on embedded details (such as fillets and chamfers) in the sketch versus including them as separate features on the solid model. Moreover, a student who has had exposure to part design in CATIA may not recognize that the Shaft command is commonly known as Revolve in other CAD packages. The definition of "correct" in CAD can be very subjective.

In order to include CAD concepts in the CI, items must assess important fundamental concepts in a manner that is applicable across CAD software packages and independent of instructor background.

\section{Background}

A Concept Inventory is a tool that uses a multiple choice assessment with carefully chosen distractors. These distractors are typically influenced by student responses to find commonly misconceived concepts. The engineering graphics CI is framed around 10 main concepts identified by a Delphi study comprised of graphics professionals [2]. More information regarding the origin of this particular CI and the Delphi study can be found in Sadowski, M and Sorby, S. 2013 and 2014.

Solid modeling constructs were identified as important by the Delphi panel [3] but the pilot study of the CI using the original CAD-related questions developed by the researchers did not yield usable data. Therefore, a survey was given to graphics experts who were gathered in Daytona Beach in January 2016 to gauge the suitability of CAD items in an engineering graphics Concept Inventory. Thirteen of the 21 experts said that CAD applications are not concepts, 2 said that they are concepts, and the remaining 6 were marginal. One expert said that they are not concepts "for the same reasons Microsoft Office applications are not concepts. [CAD] is a tool used to visualize concepts." Most of the graphics experts who took the survey said that CAD applications are not concepts; CAD is a tool that can help improve the understanding of graphics concepts. This was an indication that the CI should only focus on the traditional topics. However, with a variety of "correct" and "incorrect" modeling methods it was important to investigate whether CAD could be broken down to fundamental practices that would be acceptable regardless of instructor background, manufacturing process and CAD package. This would determine whether CAD is a concept.

\section{Method}

A pilot study of the engineering graphics assessment was administered to engineering and engineering technology students at four different universities. Based upon the results of the pilot study a test map was created identifying the list of items to test the various graphics concepts. This formed the alpha version of the instrument. The difficulty and discrimination of each item from the alpha test was used to identify viable questions for use in the beta edition which was to include both traditional and CAD test items. 
Two versions of the beta edition instrument were administered at four different universities with a total of 859 participants. The participants from Embry-Riddle Aeronautical University (26.0\%) were sophomore students enrolled in engineering science courses who had taken the graphical communication course no more than a year prior. Participants from Penn State Behrend (6.7\%) were students enrolled in a first-year engineering course who had just completed 8 weeks of instruction on graphics. The participants from Purdue University (53.8\%) were engineering technology students enrolled in the Introduction to Graphics and Solid Modeling course where they learned about the development of spatial skills and were introduced to solid modeling techniques. The students from The Ohio State University (13.5\%) were first-year engineering students enrolled in an introduction to graphics language as well as technology students enrolled in an introductory computer graphics application course. The instrument was administered through Qualtrics which evenly assigned participants to one of the two versions of the instrument.

The instrument was comprised of two different test versions, the red and the blue version. Thirteen out of the 82 total items used in the two versions were identified as suitable CAD items. Six CAD items were used in the red version and 7 CAD items for the blue version. Table 1 summarizes the CAD concepts assessed by each item in each version of the test. Each concept listed is tested in both versions, and there were two questions on constraints for the blue version.

Table 1: CAD Concepts Covered in Beta edition

\begin{tabular}{|c|c|c|c|}
\hline \multicolumn{2}{|c|}{ Red Version } & \multicolumn{2}{c|}{ Blue Version } \\
\hline Item Number & Concept & Item Number & Concept \\
\hline $\mathbf{1 0 1 2 . 0}$ & Extrude & $\mathbf{1 0 1 4 . 0}$ & Extrude \\
\hline $\mathbf{1 0 2 7 . 0}$ & Loft & $\mathbf{1 0 1 6 . 0}$ & Revolve \\
\hline $\mathbf{1 0 3 0 . 0}$ & Sweep & $\mathbf{1 0 2 6 . 0}$ & Loft \\
\hline $\mathbf{1 0 4 5 . 0}$ & Revolve & $\mathbf{1 0 2 9 . 0}$ & Sweep \\
\hline $\mathbf{1 0 6 8 . 0}$ & Planes & $\mathbf{1 0 6 7 . 0}$ & Planes \\
\hline $\mathbf{1 1 6 7 . 0}$ & Constraints & $\mathbf{1 1 5 8 . 0}$ & Constraints \\
\hline & & $\mathbf{1 1 6 7 . 0}$ & Constraints \\
\hline
\end{tabular}

Each CAD item contained a solid model of an object with a question pertaining to the modeling process. Figure 2 shows an example of a CAD question similar to one used in the CI to assess student knowledge of the Loft command. 


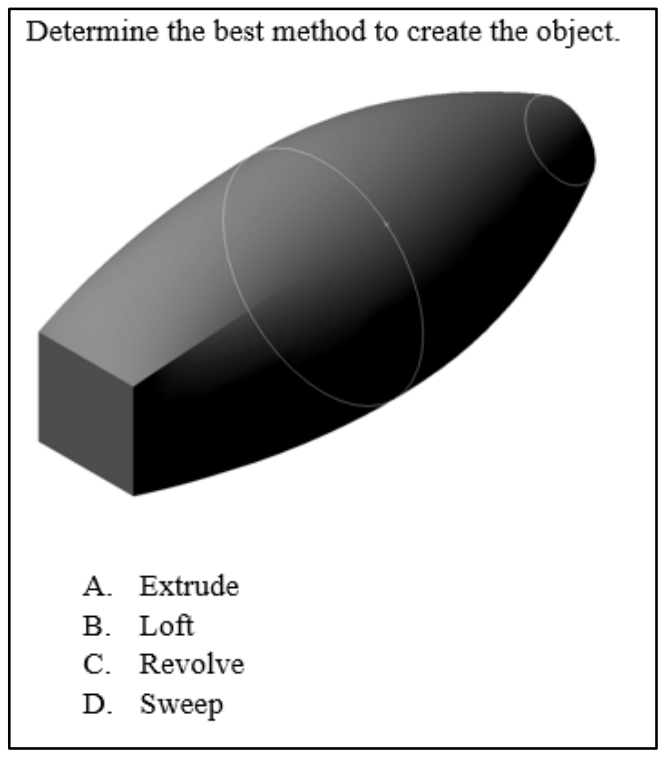

Figure 2: Sample CAD Question

Distractors A and D are incorrect because both operations require a constant cross-section. Some participants might identify the circular portion of the object and select distractor $\mathrm{C}$ which is incorrect because the Revolve operation cannot yield a square cross section. Participants who correctly recognize that the object is created using different cross-sections will select the correct response $-\mathrm{B}$.

For the beta edition of the CI the difficulty and the discrimination were calculated. The difficulty index is used to indicate how challenging each problem is based on the number of students who answered the problem correctly versus the number of students who attempted the problem. A lower difficulty index denotes an easier problem. The discrimination index is used to quantify how well high performers respond to each problem in contrast to the number of low performers that responded incorrectly. In general, the students who respond to the item correctly also did well on the test, while those who responded to the item incorrectly also tended to do poorly on the overall test. The top $27 \%$ of performers were considered high performers; the bottom $27 \%$ were considered low performers. In a paper written by Weimur and Jurs (page 145, 1990) it was stated that " $27 \%$ is used because it has shown that this value will maximize differences in normal distributions while providing enough cases for analysis." This categorization was used to determine the discrimination index. A well framed test will have a balanced combination of easy, medium, and difficult problems all having a high discrimination. The difficulty index and discrimination index are given by Equations 1 and 2, respectively.

$$
\begin{gathered}
D=100-\frac{C}{N} * 100 \\
R=\frac{(H-L)}{0.27 * N}
\end{gathered}
$$


Where $\mathrm{D}$ is the difficulty index, $\mathrm{C}$ is the number of correct responses, $\mathrm{N}$ is the total number of students who attempted the question, $\mathrm{R}$ is the discrimination index, $\mathrm{H}$ is the number of high performers, and $\mathrm{L}$ is the number of low performers.

The categorizations of the difficulty index and the discrimination index as determined by the research team for the best version of the CI are summarized in Table 2 and Table 3, respectively.

Table 2: Categorization of the Difficulty Index

\begin{tabular}{|c|c|}
\hline Range & Difficulty Level \\
\hline 0 & Very Easy \\
\hline $21-40$ & Easy \\
\hline $41-60$ & Average \\
\hline $61-80$ & Difficult \\
\hline $81-100$ & Very Difficult \\
\hline
\end{tabular}

Table 3: Categorization of the Discrimination Index

\begin{tabular}{|c|c|}
\hline Range & Verbal Description \\
\hline 0.40 \& Above & Very Good Item \\
\hline $0.30-0.39$ & Good Item \\
\hline $0.20-0.29$ & Fair Item \\
\hline $0.09-0.19$ & Poor Item \\
\hline
\end{tabular}

Questions from the alpha version were selected to have a range of difficulty from very easy to very difficult and to have a good discrimination index i.e. near to or above 0.30 .

Reliability is a measure of the precision of the instrument. The Kuder-Richardson Formula 20 (KR20) was calculated to give the reliability index of the assessment. The KR20 value ranges from 0 to 1 where a value above 0.70 is considered reliable.

\section{Results}

Table 4 presents the data comparison between the two versions of the test for the CAD items only. The mean and median (when normalized) are comparable between both versions of the test.

Table 4: Beta Instrument Metrics - CAD Items Only

\begin{tabular}{|c|c|c|}
\hline & Red Version & $\begin{array}{c}\text { Blue } \\
\text { Version }\end{array}$ \\
\hline $\begin{array}{c}\text { Number of } \\
\text { Items }\end{array}$ & 6 & 7 \\
\hline Max Score & 6 & 7 \\
\hline
\end{tabular}




\begin{tabular}{|c|c|c|}
\hline Min Score & 0 & 0 \\
\hline Mean & $3.84(64.0 \%)$ & $\begin{array}{c}4.61 \\
(65.9 \%)\end{array}$ \\
\hline Median & $4(66.7 \%)$ & $5(71.4 \%)$ \\
\hline $\begin{array}{l}\text { Standard } \\
\text { Deviation }\end{array}$ & 1.41 & 1.71 \\
\hline Variance & 1.99 & 2.93 \\
\hline
\end{tabular}

The KR20 of the CAD items alone would not be a good indication of the reliability of the instrument because there were a limited number of CAD items. Table 5 shows the KR20 with traditional and CAD items versus traditional concepts only for both versions of the test. The data is reliable with or without the CAD items as the difference between the KR20 is not significant.

Table 5: Reliability Comparison of Red Version and Blue Version

\begin{tabular}{|c|c|c|}
\hline & Red Version & $\begin{array}{c}\text { Blue } \\
\text { Version }\end{array}$ \\
\hline $\begin{array}{c}\text { KR20 with } \\
\text { traditional and } \\
\text { CAD items }\end{array}$ & 0.84 & 0.85 \\
\hline $\begin{array}{c}\text { KR20 with } \\
\text { traditional } \\
\text { concepts only }\end{array}$ & 0.83 & 0.83 \\
\hline
\end{tabular}

Figure 3 shows the frequency distribution of scores for only the CAD questions. The red version of the test (which had 6 CAD items) is more normally distributed while the blue version of the test is positively skewed.

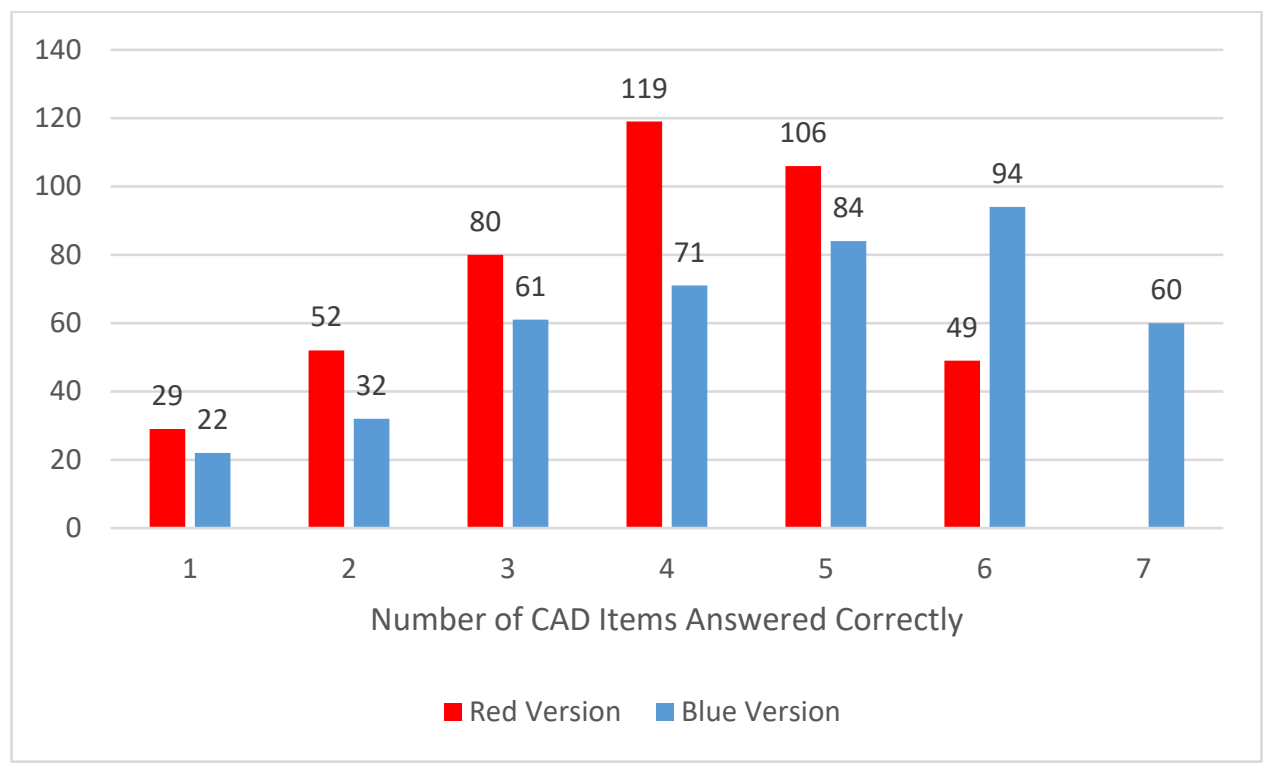

Figure 3: Frequency Distribution for CAD Items Only 
Table 6 shows the comparison of CAD items by concept. Both versions of the test had questions similar in difficulty and discrimination for each CAD concept tested which indicates potential for a pre-test and a post-test.

Table 6: Difficulty and Discrimination Index Sorted by Concept

\begin{tabular}{|c|c|c|c|c|}
\hline Concept & Version & $\begin{array}{c}\text { Difficulty } \\
\text { Index }\end{array}$ & $\begin{array}{c}\text { Difficulty } \\
\text { Level }\end{array}$ & $\begin{array}{c}\text { Discrimination } \\
\text { Index }\end{array}$ \\
\hline \multirow{2}{*}{ Extrude } & Red & 27 & Easy & 0.63 \\
\cline { 2 - 5 } & Blue & 22 & Easy & 0.59 \\
\hline \multirow{3}{*}{ Constraints } & Red & 39 & Easy & 0.52 \\
\cline { 2 - 5 } & Blue & 37 & Easy & 0.65 \\
\cline { 2 - 5 } & Blue & 42 & Average & 0.31 \\
\hline \multirow{2}{*}{ Loft } & Red & 56 & Average & 0.68 \\
\cline { 2 - 5 } & Blue & 46 & Average & 0.69 \\
\hline \multirow{2}{*}{ Planes } & Red & 28 & Easy & 0.51 \\
\cline { 2 - 5 } & Blue & 29 & Easy & 0.63 \\
\hline \multirow{2}{*}{ Revolve } & Red & 30 & Easy & 0.45 \\
\cline { 2 - 5 } & Blue & 18 & Very & 0.39 \\
\hline \multirow{2}{*}{ Sweep } & Red & 36 & Easy & 0.59 \\
\cline { 2 - 5 } & Blue & 44 & Average & 0.73 \\
\hline
\end{tabular}

Table 7 presents the same data sorted by test version. The red version of the test is marginally more difficult but both tests have similar discrimination indices.

Table 7: Difficulty and Discrimination Index Sorted by Test Version

\begin{tabular}{|c|c|c|c|c|c|}
\hline Version & Concept & Difficulty & $\begin{array}{c}\text { Difficulty } \\
\text { Index } \\
\text { Average }\end{array}$ & $\begin{array}{l}\text { Discrimination } \\
\text { Index }\end{array}$ & $\begin{array}{l}\text { Discrimination } \\
\text { Index Average }\end{array}$ \\
\hline \multirow{6}{*}{ Red } & Extrude & 27 & \multirow{6}{*}{36} & 0.63 & \multirow{6}{*}{0.56} \\
\hline & Loft & 56 & & 0.68 & \\
\hline & Sweep & 36 & & 0.59 & \\
\hline & Revolve & 30 & & 0.45 & \\
\hline & Planes & 28 & & 0.51 & \\
\hline & Constraints & 39 & & 0.52 & \\
\hline \multirow{4}{*}{ Blue } & Extrude & 22 & \multirow{4}{*}{34} & 0.39 & \multirow{4}{*}{0.54} \\
\hline & Loft & 46 & & 0.69 & \\
\hline & Sweep & 44 & & 0.73 & \\
\hline & Revolve & 18 & & 0.39 & \\
\hline
\end{tabular}




\begin{tabular}{|l|c|c|c|c|}
\hline & Planes & 29 & \multirow{4}{*}{} & 0.63 \\
\cline { 2 - 3 } & Constraints & 37 & & 0.65 \\
\cline { 2 - 3 } & Constraints & 42 & & 0.31 \\
\hline
\end{tabular}

\section{Analysis}

The red version and the blue version of the test are similar. They both were comprised of questions that were average, easy or very easy. Even though some concepts were more difficult than others there were no difficult or very difficult questions. Testing CAD may be important, but students find these 13 test items easy. The data shows good discrimination for the CAD items but with so few CAD items the discrimination is not very meaningful. The KR20 of the isolated CAD items is below 0.70 because the number of items is insufficient and therefore the data concerning only the CAD items is unreliable.

\section{Conclusion}

Even though the use of CAD items contributes to the overall reliability of the instrument, when isolated the CAD items do not provide much information on student knowledge because of the low difficulty of the questions. In order for the discrimination index to provide a significant indication of the quality of the questions there need to be more than 6 or 7 items. Having at least 20 items with multiple questions per topic could be more indicative of student performance on CAD items, however this would make the CI excessively long. Additionally, a standardized CAD assessment could be difficult to develop because correct responses may vary based on instructor background and CAD tool used. A separate assessment with more items could be developed to measure student learning solely on CAD, but expert feedback has indicated that CAD in itself is a tool and not a concept and as such should not be included in the Concept Inventory at this time. Many of the skills necessary to create effective CAD models, regardless of the software or preferred technique, are already assessed in the CI as it currently exists, including parallel projection theory, planar geometry, and drawing conventions, and the results of these questions can help inform an instructor on their students' knowledge of the information needed to build effective models.

The authors gratefully acknowledge the support of the National Science Foundation for this project through collaborative grants DUE-1432280 and DUE-1432288. 


\section{References}

[1] Marbach-Ad G., McAdams K. C., Benson S., Briken V., Cathcart L., Chase M., El-Sayed N. M., Frauwirth K., Fredericksen B., Joseph S. W., Lee V., McIver K. S., Mosser D., Quimby B. B., Shields P., Song W., Stein D. C., Stewart R., Thompson K. V., Smith A. C. (2010) A Model for Using a Concept Inventory as a Tool for Students' Assessment and Faculty Professional Development, University of Maryland, College Park, MD.

[2] Sadowski, M., \& Sorby, S. (2013). Update on a Delphi Study for Developing a Concept Inventory for Engineering Design Graphics. Engineering Design Graphics Division 68th MidYear Meeting Proceedings, Worchester, MA.

[3] Sadowski, M., \& Sorby, S. (2014). Defining Concepts for an Engineering Concept Inventory: A Delphi Study. Proceedings of the 69th Midyear Meeting of the Engineering Design Graphics Division of ASEE, Normal IL. 67-72.

[4] Wiersma, W. \& Jurs, S.G. (1990). Educational measurement and testing (2nd Ed.). Boston, MA: Allyn and Bacon.

[5] Shartrand, A., Weilerstein, P., Besterfield-Sacre, M., Olds, B. M. (2008) "Assessing student learning in technology entrepreneurship," 2008 38th Annual Frontiers in Education Conference, Saratoga Springs, NY.

[6] Hestenes, D., Wells, M., Swackhamer, G. Force Concept Inventory. The Physics Teacher, Vol. 30

[7] D. L. Evans et al. (2003) "Progress on concept inventory assessment tools," 33rd Annual Frontiers in Education, 2003. FIE 2003. pp. T4G-1-8 Vol.1.

[8] Streveler, R. A., Litzinger, T. A., Miller, R. L. and Steif, P. S. (2008), Learning Conceptual Knowledge in the Engineering Sciences: Overview and Future Research Directions. Journal of Engineering Education, 97: 279-294. 